\title{
Research on O2O Service Encounter of Theme Hotel Based on Customer Experience
}

\author{
Fengzhi Sun, Yanju Jia*, Rui Liu, Tingting Bi, ChenShan Ouyang \\ Business School \\ Shandong Normal University \\ Jinan, China \\ fz7077@163.com.yanjujia@126.com.liurui940524@163.com.1826490795@qq.com.495431792@qq.com
}

\begin{abstract}
With the social and economic development, the consumers not only experience the product function elements in the hotel, but also experience the spiritual elements such as product culture, personality and memory. The theme hotel can adapt to the changes in consumer demands and becomes a new development tren $6 \mathrm{~d}$ in the hotel industry in the future. As an increasingly number of hotels becomes the theme hotel, it challenges the sustainable development of the theme hotel. How to improve the customer experience value and obtain more loyal customers has become the key problem to be solved in the future development of the theme hotel. This paper explores the relationship between 020 service encounter, customer experience value and customer loyalty from the perspective of service encounter, and concludes that the five dimensions of O2O service encounter positively affect the emotional functional value, the environmental facility encounter, service personnel encounter and online information encounter positively affect the social cognitive value through the structural equation model; the experience value positively affects customer loyalty and plays the mediating function between $\mathrm{O2O}$ service encounter and customer loyalty. The paper brings some inspiration for the future development of theme hotel based on the research conclusions.
\end{abstract}

Keywords-O2O service encounter; experience value; theme hotel; customer loyalty

\section{INTRODUCTION}

With the change of development mode, optimization of economic structure and the transformation of growth momentum, China's economy has changed from the highspeed growth stage to high-quality development stage, the decision-making psychology of consumers in choosing the commodities has changed from the earliest functional consumption to the subsequent brand consumption and to the experiential consumption that has recently become popular, and the customers have put forward the higher requirements for quality accommodation experience. How to integrate creativity and emotion into the theme and service, create the wonderful experience for customers, make the experience become a memory after consumption, leave an unforgettable memory for consumers, and satisfy the customer' individualized needs is key to success for hotel industry in the market competition. On this background, the theme hotel appears. The market gradually tends to pursue differentiation, specialization and individuality, become innovative, cultural and experiential, integrate the culture, idea and emotion into products and services to create a new lifestyle that cannot be imitated and replicated, and provide customers with the highly innovative, experiential and cultural products and services. In the era of mobile Internet, the service form and content of the theme hotel have changed accordingly, and the connotation of service encounter between customers and hotels has been continuously enriched, developing from the initial interpersonal interaction [1-3] to the encounter of the whole service process [4-6], including offline encounter with service personnel, service environment and customers, as well as online encounter based on network platform, namely, $\mathrm{O} 2 \mathrm{O}$ service encounter. A series of service encounters finally affects the customer experience, and the customer experience value is an important factor in determining the customer behavior intention [7]. The establishment of customer loyalty depends on the experience value obtained in the service process.

\section{RELEVANT CONCEPTS AND BASIC THEORIES}

\section{A. Customer Loyalty}

The academic circles have performed a lot of research on customer loyalty from the concepts, measurement and influence factors, and the research has tended to be mature. It believes that customer loyalty is a kind of customer preference for enterprise products and services, and leads to a series of behaviors such as recommendation and repurchases [8-10]. As people's needs for a better life become more and more extensive, the customer loyalty is no longer simply established by satisfying the customers' consumption needs, but it should be established by creating a warm atmosphere, designing the humanized and personalized service, and providing the creative and story-like products to make the customers to feel valued. It can be said that the customers will be loyal to those who makes customers feel affection. Therefore, the customer loyalty is the customers' action to voluntarily advertise and repurchase the products or service for the enterprises because the enterprises create a warm atmosphere, design the humanized and personalized service, and provide the creative and story-like products to make the customers to feel valued, highly identify with and satisfy with the enterprises' products or service and form a preference attitude.

\section{B. Value Experience}

The customer value theory that the experiential value concept comes from the marketing is generated in the context of experience economy. Zaithaml puts forward the concept of "customer perceived value", which is defined as a kind of evaluation made after comparing the customer perceived cost with the cost paid [7]; Kotler puts forward the "delivered value", which is defined as the difference between the total 
value perceived by the customer and the total cost it consumes [11]; as the in-depth researches are conducted, the scholars believe that the connotation of the experience value mainly refers to the customers' experience perception and overall evaluation during the consumption process [12-13]. There is no unified view on the dimension division of experience value, mainly including the hierarchical, introspective and related experience value structure models [13-15]. The hierarchical experience value model studies the customer experience value from customer demand, which complies with the requirements of the times. Therefore, this paper uses the hierarchical experience value model as the theoretical basis to research the experience value, and divides the experience value into two dimensions: emotional functional value and social cognitive value.

\section{Service Encounter}

The research on service encounter extends from the original narrow concept based on interpersonal interaction to the generalized whole-process encounter concept, mainly focusing on researching the offline encounter, namely physical environment encounter, service personnel encounter and customer encounter [16]. In the context of the mobile Internet era, the customers form a first impression on the hotel and have the certain psychological anticipation through online information before they go to the hotel; in the consumption process, the customers form the consumption experience through encounter with the hotel hardware and software, and the satisfaction degree of customer expectations in the first two stages has formed the customer loyalty; after consumption, the customers will make the word-of-mouth publicity through online evaluation, including positive publicity and negative publicity. The customers complete the whole consumption process through pre-consumer, inconsumer and post-consumer service encounters. It is obvious that the traditional offline-based service encounter is not enough to represent the encounter of the whole consumption process, and it is necessary to add the online encounter elements in the customer encounter between the customers and theme hotels, not only focus on improving the hardware facilities but also prompting the culture, ideas, service and software by integration of online and offline service encounter elements to improve the pre-consumer, in-consumer and postconsumer service encounter quality. There are few researches on the new dimension-Internet-based online encounter. Some scholars have proposed the concept of self-service encounter [5], electronic service encounter [17] and intelligent interaction [18]. Therefore, this paper combines the mobile Internet era backgrounds to propose the new dimension of $\mathrm{O} 2 \mathrm{O}$ service encounter based on the traditional research, that is, the encounters between customers and tangible and intangible factors such as enterprises' physical environment, other customers, service personnel and networks in a series of whole consumption process. These factors can be divided into online and offline parts.

\section{Theme Hotel}

The scholars research the theme hotel mainly study from the concept, characteristics and development etc. Most scholars believe that the theme hotel takes the specific culture as the theme, creates a specific cultural atmosphere based on the theme, is characterized by culture, difference and experience to provide customers with the high-quality service experience [69-72]. In terms of development, the scholars mainly propose the following development suggestions such as correct positioning, focusing on innovation, exploring cultural connotation, and creating theme atmosphere from the theoretical level. However, there is lack of the practical research on the establishment of customer loyalty in theme hotels. Through summarizing the definitions made by the scholars in the literature review, it can be found that the theme hotel is different from the traditional hotel, it provides not only products, but also the ideas, culture and intimate service, provides each customer with custom-made service to make the customer emotionally satisfied and happy in the consumption process and focusing on the culture, specificity and experience characteristics based on the customer experience and by creating value through service. The culture is the soul of the theme hotel. This culture is reflected in the hotel hardware and software and permeated into the whole hotel operation and service process; the specificity requires the theme hotel paying attention to innovation and establishing the characteristics with ideas, which is the key factor that makes the theme hotel different; the experience is the most important characteristics of the theme hotel, requiring the hotel providing the products and services which can make the customers feel the affection, experiencing the story behind the theme and leave good memories after experience.

In summary, this paper defines the theme hotel as one form of hotel that takes the specific culture as the theme, reflect this culture in the hotel hardware facilities, environment atmosphere and service, provide customers with specialized and personalized service based on the customer experience and satisfy the customers' deeper needs for pursuit of individuality, happiness and enjoyment by creating value through service.

The scholars research the customer loyalty influence factors from many aspects, mainly including service encounter, experience value, psychological contract, relationship quality, perceived value and customer satisfaction. However, at present, there is relatively little research on how to establish the customer loyalty in theme hotels. Furthermore, with the advent of the experience economy era, the service experience increasingly affects the customer loyalty. Therefore, this paper takes the theme hotel as the research object, provides suggestions on how to establish the customer loyalty in the theme hotels based on $\mathrm{O} 2 \mathrm{O}$ service encounter and experience value to enrich the practice research results of theme hotels.

\section{THEORETICAL MODELS AND RESEARCH HYPOTHESES}

For the dimension of $\mathrm{O} 2 \mathrm{O}$ service encounter, scholars have conducted sufficient researches on offline encounter, and have basically determined the corresponding dimensions. In this paper, the dimension of offline encounter is divided into three elements, including environment facility encounter, other customer encounter, and service personnel encounter. For online encounter, based on the concepts proposed by scholars, such as self-service encounter [5], e-service 
encounter [17] and intelligent interaction [18], and combined with concrete situations of theme hotels, this paper refines and divides the dimension of online encounter into online information encounter and intelligent interaction encounter. For the dimension of experience value, scholars proposed three dimensions, including functional dimension, emotional dimension and social dimension [19]. Based on opinions of scholars, and combined with research situations, this paper proposes two dimensions, emotional functional value and social cognitive value. In order to test the structure of variable dimension, this paper conducts exploratory factor analysis and the results supports the dimension division of variables.

\section{A. O2O Service Encounter and Experience value}

The quality of encounter between customers and the various elements of theme hotel directly affects the overall consumption experience of customers, which in turn affects the experience value [18]. In terms of the correlation between online encounter and experience value, physical environment encounter significantly affects the customer's interesting experience and aesthetic experience. The physical environment of the overall atmosphere, catering, guest rooms and other products in the theme hotel can stimulate customers and influence their experience value. Customer evaluation of the service personnel's professional competence and efficiency will significantly affect their experience value. Interactions between customers can also have a significant impact on customer experience value and behavioral intentions. Customer interaction and encounter with the service environment, service personnel, and other customers will affect their consumer experience [16]. For the correlation between online encounter and experience value, the interaction between customers and the Internet in the Internetbased service encounter has a certain impact on the customer experience value, and can provide customers with better experience value[20]. Self-service device encounter based on mobile internet can also significantly affect customer experience value [21]. Therefore, this paper proposes the following hypotheses:

\section{H1: Offline service encounter positively influences experience value \\ H2: Online service encounter positively influences experience value}

\section{B. O2O Service Encounter and Customer Loyalty}

As people focus more on consumption experience, the theme hotel customer loyalty is increasingly dependent on the encounter experience between the customer and the hotel, and the improvement of encounter quality has a significant effect on improving customer loyalty. In terms of the correlation between offline service encounter and customer loyalty, there is significant positive correlation between the physical environment encounter, service personnel encounter, and other customer encounter, with customer loyalty [18]. Due to the use of information technology, hotels have begun to use self-service technology such as websites to conduct customer service. The quality of encounter between customers and selfservice technology has a significant impact on customers' repeated purchase behavior [7]. Customer experience with e- service encounter can significantly affect their evaluation of corporate products and services, which in turn affects their loyalty to the business [18]. Therefore, this paper proposes the following hypotheses:

\section{H3: Offline service encounter positively influences customer loyalty}

\section{H4: Online service encounter positively influences customer loyalty}

\section{Experience Value and Customer Loyalty}

The customer experience is an important factor in determining the customer's intention to act. A bad consumer experience will disappoint customers so that customers will not buy products and services again, and will also influence the behavior of potential customers through word of mouth, leading to disloyalty. A good consumer experience increases the willingness of customers to patronize again and recommends others to consume, resulting in customer loyalty. Service encounter indirectly affects customer behavioral intention through experience value [18]. Customer experience value positively influences customers' repurchase intentions [22]. Therefore, this paper proposes the following hypotheses:

\section{H5: Experience value positively influences customer loyalty}

Finally, the theoretical model and research hypothesis diagram of this paper are established, as shown in Figure 1:

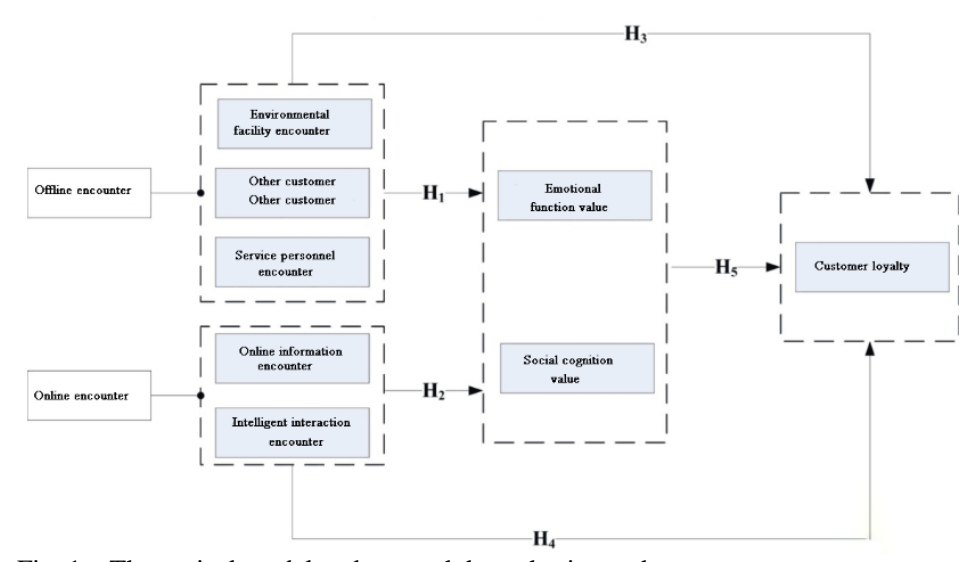

Fig. 1. Theoretical model and research hypothesis graph

\section{RESEARCH DESIGN}

\section{A. Variable Measurement and Questionnaire Design}

In this Paper, questionnaire is used to obtain data. The measurement items of all variables in the questionnaire refer to the existing maturity scale and are modified appropriately according to the specific situation of theme hotel. O2O service encounter scale mainly adopts the service encounter scale proposed by $\mathrm{Wu} \&$ Liang [16] and the measurement scale is improved and supplemented from such three dimensions as physical environment encounter, other customer encounter and service personnel encounter of offline encounter according to the research situation of theme hotel and then 15 items are put forward; for the dimension of online encounter, 
combined with some measurement dimensions of electronic service encounter (online encounter) proposed by scholars[18], six items in two dimensions of online information encounter and intelligent interactive encounter are proposed, and the variable is measured with 21 measurement items finally. The experience value uses the experience value scale proposed by Sweeney and Zhao Xiaoxiao et al. [23-24], there are 12 measurement items in total. The measurement scale related to customer loyalty is mature relatively and this Paper refers to the customer loyalty scale proposed by Zeithaml [25], Yang Jie [26] and other scholars. Therefore, there are 4 measurement items.

The content of the questionnaire is composed of three parts: introduction, basic information of customer and variable measurement item. In introduction part, the purpose, use and confidentiality commitment of the questionnaire are explained. The basic information of customer includes gender, age, occupation, income, accommodation characteristics of customer and other information; the impact of $\mathrm{O} 2 \mathrm{O}$ service encounter on the customer loyalty of theme hotel is measured with such three measurement scales as $\mathrm{O} 2 \mathrm{O}$ service encounter, experience value and customer loyalty, containing 39 measurement items in total. All the three scales are used to measure the different attitudes of the subjects by using the Liken 5 level scale, which shows "totally disagree" (1) and "totally agree" (5) from 1 to 5 .

\section{B. Data Collection}

This Paper takes the theme hotels in Shandong Province as the research object. The time of data collection is from September 2017 to January 2018. 15 Golden Star cultural theme hotels and 10 Silver Star cultural theme hotels in the Province were included in the research in the manner of online and offline study. A total of 1000 paper questionnaires were distributed in the field. After screening the validity of the questionnaires, a total of 897 valid questionnaires were obtained and the effective rate was $89.7 \%$. For online study, "SO JUMP" software was mainly used to prepare questionnaires and release the questionnaire link on the WeChat Official Account of the hotels for data collection. A total of 989 electronic questionnaires were collected and 838 valid questionnaires were obtained through the validity screening. The effective rate was $84.7 \%$. In both online and offline study, a total of 1989 questionnaires were distributed and 254 invalid questionnaires are deleted. A total of 1735 valid questionnaires were obtained and the effective recovery rate was $87.2 \%$.

In terms of gender, the proportion of women is $52.68 \%$ and that of men is $47.32 \%$, indicating that the proportion of men and women in the survey is more balanced, it means that the sample is representative; in terms of age distribution, the people aged 25 to 44 accounts for the vast majority, $82.13 \%$ in total. It can be seen that the consumer group of theme hotel is mainly the population with stable income, which is in line with the actual situation; in terms of occupation distribution, the number of respondents in private enterprises, government administration/public institutions and state-owned enterprises is great, accounting for $38.27 \%, 28.36 \%$ and $12.57 \%$ respectively, and less in other occupations; In terms of educational background, the proportion of undergraduate/junior college students is more than half, namely $66.74 \%$, followed by that of master or above, which is $24.32 \%$, indicating that the consumer group of theme hotel is generally highly educated, which is consistent with the distribution of occupation. Therefore, the credibility of the data is high; in terms of personal income, the proportion of consumer with monthly income within the range of 5000 yuan to 8000 yuan is higher, that is $49.34 \%$, followed by the proportion of 3000 yuan to 5000 yuan, that is $23.17 \%$, indicating that the income level of the main consumer groups in theme hotel is at the middle income level. This result is basically consistent with the distribution of age, occupation and education; in terms of the staying times, the proportion of most customers who stay at the hotel for the first time is $51.47 \%$, and that of customer who have stayed at the hotel for more than three times is $36.48 \%$, which is relatively high, indicating that these theme hotels have had a group of loyal customers; it is shown from above data that the research objects basically cover the individual characteristics of different samples and represent different customer groups, which better reflect the actual situation of theme hotel customers and have certain representativeness.

\section{Data Analysis \\ Reliability analysis}

The Cronbach $\alpha$ coefficient is used to analyze the scale reliability. The Cronbach $\alpha$ value of the overall scale is 0.924 , which is greater than the corresponding standard 0.7. The Cronbach $\alpha$ value of each dimension in the model is between 0.735 and 0.915 , which is also greater than the corresponding standard 0.7, indicating that the questionnaire measurement in this paper has good reliability.

\section{Structural equation model analysis}

The structural equation model consists of the measurement model and the structural model. The measurement model is used to reflect the relationship between latent variables and observed indicators in the model, while the structural model is used to reflect the relationship between latent variables [27].

In this paper, the maximum likelihood method is used for measurement model analysis, the $\chi 2 / \mathrm{df}$ of the measurement model is 2.230 , with GFI of 0.923 , RMSEA of 0.043 , NFI of 0.946 , CFI of 0.902, IFI of 0.905, PCFI of 0.702, and all the fitting parameters meet the standard [27], the model passes the test of goodness of fit.

Table 1 shows that the normalized factor load of all items in their respective measurement dimensions is between 0.521 and 0.940 , all of them are higher than 0.5 , the corresponding $t$ value is between 8.095 and 25.657 and the $P$ value is significant; CR is greater than the standard 0.6, indicating that the observed indicators of latent variables have good convergence validity. 
TABLE I. VALIDITY ANALYSIS TABLE

\begin{tabular}{|c|c|c|c|c|c|}
\hline Variable & $\begin{array}{c}\text { Measure } \\
\text {-ment } \\
\text { item }\end{array}$ & $\begin{array}{l}\text { Factor } \\
\text { load }\end{array}$ & T value & AVE & CR \\
\hline \multirow{7}{*}{$\begin{array}{l}\text { Environmental } \\
\text { facility } \\
\text { encounter }\end{array}$} & W1 & .589 & - & 0.524 & 0.779 \\
\hline & W2 & .658 & $9.572 * * *$ & & \\
\hline & W3 & .578 & $8.611 * * *$ & & \\
\hline & W4 & .593 & $8.889 * * *$ & & \\
\hline & W5 & .579 & $8.479 * * *$ & & \\
\hline & W6 & .589 & $8.833 * * *$ & & \\
\hline & W7 & .521 & $8.095 * * *$ & & \\
\hline \multirow{3}{*}{$\begin{array}{l}\text { Other customer } \\
\text { encounter }\end{array}$} & G1 & .859 & - & 0.689 & 0.854 \\
\hline & G2 & .919 & $21.107 * * *$ & & \\
\hline & G3 & .693 & 15.089 *** & & \\
\hline \multirow{5}{*}{$\begin{array}{l}\text { Service } \\
\text { personnel } \\
\text { encounter }\end{array}$} & F1 & 643 & - & 0.543 & 0.856 \\
\hline & $\mathrm{F} 2$ & .815 & $12.787 * * *$ & & \\
\hline & F3 & .856 & $13.254 * * *$ & & \\
\hline & F4 & .632 & $10.678 * * *$ & & \\
\hline & F5 & .724 & $11.764 * * *$ & & \\
\hline \multirow{4}{*}{$\begin{array}{l}\text { Online } \\
\text { information } \\
\text { encounter }\end{array}$} & $\mathrm{X} 1$ & .819 & - & 0.632 & 0.881 \\
\hline & $\mathrm{X} 2$ & .913 & $19.889 * * *$ & & \\
\hline & $\mathrm{X} 3$ & .767 & $16.678^{* * *}$ & & \\
\hline & $\mathrm{X} 4$ & 665 & $14.232 * * *$ & & \\
\hline \multirow{2}{*}{$\begin{array}{l}\text { Intelligent } \\
\text { interaction } \\
\text { encounter }\end{array}$} & $\mathrm{Z1}$ & .676 & - & 0.699 & 0.817 \\
\hline & $\mathrm{Z} 2$ & .989 & $19.768 * * *$ & & \\
\hline \multirow{7}{*}{$\begin{array}{c}\text { Emotional } \\
\text { function value }\end{array}$} & Q1 & .778 & - & 0.628 & 0.906 \\
\hline & Q2 & .823 & $17.879 * * *$ & & \\
\hline & Q3 & .795 & $16.786^{* * * *}$ & & \\
\hline & Q4 & .601 & $12.231 * * *$ & & \\
\hline & Q5 & .903 & $20.432 * * *$ & & \\
\hline & Q6 & .889 & $19.456 * * *$ & & \\
\hline & Q7 & .711 & $14.867 * * *$ & & \\
\hline \multirow{5}{*}{$\begin{array}{l}\text { Social cognition } \\
\text { value }\end{array}$} & S1 & .863 & - & 0.743 & 0.942 \\
\hline & $\mathrm{S} 2$ & .880 & $23.546^{* * * *}$ & & \\
\hline & S3 & .903 & $24.458 * * *$ & & \\
\hline & S4 & .854 & $21.346^{* * * *}$ & & \\
\hline & S5 & .849 & $21.567 * * *$ & & \\
\hline \multirow{4}{*}{$\begin{array}{l}\text { Customer } \\
\text { loyalty }\end{array}$} & T1 & .853 & - & 0.786 & 0.939 \\
\hline & $\mathrm{T} 2$ & .940 & $25.657 * * *$ & & \\
\hline & T3 & .908 & $24.324 * * *$ & & \\
\hline & $\mathrm{T} 4$ & .849 & $21.985 * * *$ & & \\
\hline
\end{tabular}

Table footnote: “**** means $\mathrm{P}<0.001$.

Table 2 shows that the square root of mean extraction variance of each variable is larger than the correlation coefficient between it and other variables, indicating that the latent variable has good discriminate validity.

TABLE II. ANALYTICAL STATEMENT OF DISCRIMINATE VALIDITY AND VARIABLE CORRELATION COEFFICIENT

\begin{tabular}{|c|c|c|c|c|c|c|c|c|}
\hline Variable & $\begin{array}{l}\text { Environme } \\
\text { ntal facility } \\
\text { encounter }\end{array}$ & $\begin{array}{c}\text { Other } \\
\text { customer } \\
\text { encounter }\end{array}$ & $\begin{array}{c}\text { Serice } \\
\text { personnel } \\
\text { encounter }\end{array}$ & $\begin{array}{c}\text { Online } \\
\text { informaiton } \\
\text { encounter }\end{array}$ & $\begin{array}{l}\text { Intelligent } \\
\text { interaction } \\
\text { encounter }\end{array}$ & $\begin{array}{l}\text { Emotional } \\
\text { function } \\
\text { value }\end{array}$ & $\begin{array}{c}\text { Social } \\
\text { recognition } \\
\text { value }\end{array}$ & $\begin{array}{c}\text { Custome } \\
\text { loyalty }\end{array}$ \\
\hline $\begin{array}{l}\text { Environmental } \\
\text { facility encounter }\end{array}$ & 0.723 & & & & & & & \\
\hline $\begin{array}{c}\text { Other customer } \\
\text { encounter }\end{array}$ & $0.325 * * *$ & 0.829 & & & & & & \\
\hline $\begin{array}{l}\text { Serice personnel } \\
\text { encounter }\end{array}$ & $0.220^{* * * *}$ & $0.493 * * * *$ & 0.756 & & & & & \\
\hline $\begin{array}{c}\begin{array}{c}\text { Online } \\
\text { informaiton } \\
\text { encounter }\end{array} \\
\end{array}$ & $0.368^{* * * *}$ & $0.342^{* * * * *}$ & $0.418^{* * * *}$ & 0.800 & & & & \\
\hline $\begin{array}{c}\begin{array}{l}\text { Intelligent } \\
\text { interaction } \\
\text { encounter }\end{array} \\
\end{array}$ & $0.254^{* * * *}$ & $0.209^{* * * *}$ & $0.335^{* * * *}$ & $0.474 * * * *$ & 0.834 & & & \\
\hline $\begin{array}{c}\text { Emotional } \\
\text { function value }\end{array}$ & $0.376^{* * * *}$ & $0.201^{* * * *}$ & $0.423 * * *$ & $0.263 * * *$ & $0.235^{* * * *}$ & 0.787 & & \\
\hline $\begin{array}{c}\text { Social recognition } \\
\text { value }\end{array}$ & $0.236^{* * * *}$ & $0.205^{* * * *}$ & $0.598^{* * * *}$ & $0.250^{* * * *}$ & $0.263^{* * * *}$ & $0.630^{* * * *}$ & 0.869 & \\
\hline Customer loyalty & $0.357^{* * * * *}$ & $0.236^{* * * * *}$ & $0.507^{* * * * *}$ & $0.207 *$ *** & $0.236^{* * * * *}$ & $0.655^{* * * *}$ & $0.627 * * *$ & 0.889 \\
\hline
\end{tabular}

The maximum likelihood method is used to estimate the structural model and test the proposed assumption. In the structural model, the $\chi 2 / \mathrm{df}$, GFI, RMSEA, NFI and TLI values are $2.456,0.941,0.058,0.931$, and 0.934 , respectively, which all reach the fitting standard, indicating that the model has a good overall goodness of fit.

The structural model analysis results and the normalized results of each coefficient are shown in Fig. 2. The test results partially support Assumption 1 and Assumption 2, and environmental facility encounter, other customer encounter, service personnel encounter, online information encounter and intelligent interaction encounter all positively affect the emotional function value. Environmental facility encounter, service personnel encounter and online information encounter positively affect social recognition value; Assumption 3 and Assumption 4 are not supported, indicating that $\mathrm{O} 2 \mathrm{O}$ service encounter cannot directly affect customer loyalty; while emotional function value and social recognition value positively affect customer loyalty, and Assumption 5 is supported, thus indicating that experience value plays a mediating role between $\mathrm{O} 2 \mathrm{O}$ service encounter and customer loyalty.

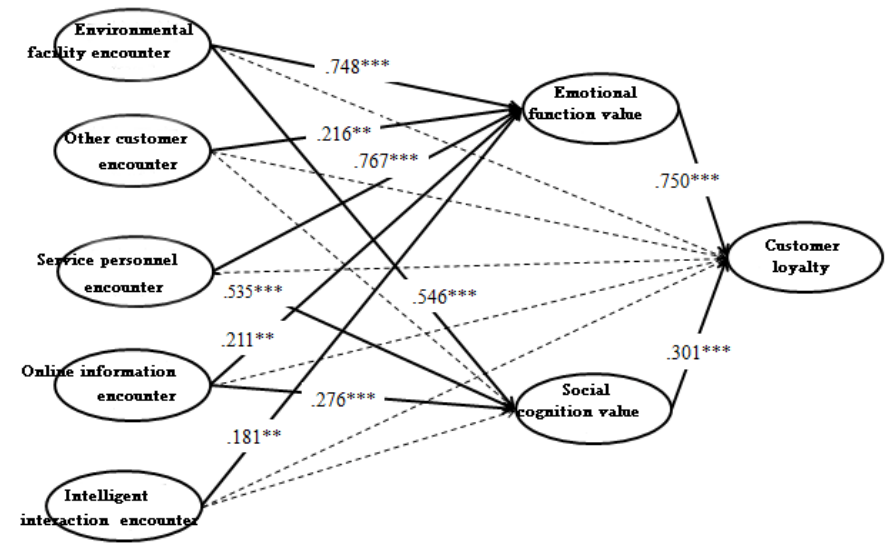

The real line represents that path coefficient passes the significance test.

The dotted line represents that the path coefficient fails to pass the significance test, indicating that the path relationship between the two connected factors is not significant.

Fig. 2. Relationship Diagram of Structural Model

\section{CONCLUSION AND ENLIGHTENMENT}

\section{A. Research Conclusion}

By virtue of structural equation model, this paper explored the relationship among $\mathrm{O} 2 \mathrm{O}$ service encounter, experience value and customer loyalty and concludes as follows:

1) Composition of $\mathrm{O} 2 \mathrm{O}$ service encounter factors: Five factors of $\mathrm{O} 2 \mathrm{O}$ service encounter, including the environmental facility encounter, other customer encounter, service personnel encounter, online information encounter and intelligent interaction encounter, extracted from factor analysis can explain $65.567 \%$ overall variation, which is the same as the measurement dimension through interrelations of literature in this paper. 
2) Composition of experience value factor: Two factors of experience value extracted from factor analysis can explain $74.216 \%$ overall variance, in which the emotion value and function value fall into the same factor, and social value and cognitive value fall into the same factor, which are different from the dimensions proposed by the hypotheses in this paper. Therefore, this paper believes that the theme hotel customers have similar experiences on emotional and functional values, as well as similar experiences on the social and cognitive values. On that account, these two factors are named as the emotional functional value and social cognitive value.

3) Composition of customer loyalty factors: This paper finds, through factor analysis, that the attitude loyalty and behavior loyalty of the theme hotel customers fall into the same factor, which explains $84.039 \%$ overall variation, indicating that the customers' attitude loyalty and behavior loyalty are of similarity, so that the writer integrates the attitude loyalty and behavior loyalty of theme hotel customer into one factor - customer loyalty.

4) Relationship between $\mathrm{O} 2 \mathrm{O}$ customer encounter and customer experience value: Three dimensions of offline encounter, including service personnel encounter, environmental facility encounter and other customer encounter, and two dimensions of online encounter, including the intelligent interaction encounter and online information encounter, all positively affect the emotional functional value, with relation path coefficient respectively at 0.776 , $0.759,0.206,0.179$ and 0.171 , so that the theme hotels shall pay attention to the improvement of customers' emotional functional value from five dimensions of $\mathrm{O} 2 \mathrm{O}$ service encounter, in which, special attention shall be paid to the service personnel and environmental facility encounters; Environmental facility encounter and service personnel encounter in the offline encounter, and online information encounter in the online encounter all positively affect the social cognitive value, with route coefficient respectively at $0.564,0523$ and 0.261 , so that the theme hotels shall boost the customers' social cognitive value from the environmental facility, service personnel and online information, with a particular attention to the optimization of environmental facility and service personnel encounters.

5) Relationship between $\mathrm{O} 2 \mathrm{O}$ service encounter and customer loyalty: five dimensions of $\mathrm{O} 2 \mathrm{O}$ service encounter all have no direct positive influence on the customer loyalty, but affect the customer loyalty directly through the experience value. Hence, the theme hotels shall provide the good consumption experience by virtue of quality improvement in $\mathrm{O} 2 \mathrm{O}$ service encounter, to increase the experience value of customers, so as to enhance the customer loyalty.

6) Relationship between the customer experience value and customer loyalty: The dimensions - emotional functional value and social cognitive value in the customer experience value can positively affect the customer loyalty, with path coefficient respectively at 0.750 and 0.209 , showing that the consumption experience of the customers in theme hotels directly affect their loyalty, so that the theme hotels shall pay more attention to the customers' experience in emotion and cognition, to meet the deep consumption demand of the customers and lay a solid foundation for the establishment of customer loyalty.

\section{B. Enlightenment on The Study}

Obtaining and maintaining customer loyalty is the key to gain competitive advantage and 020 service encounter and experience value play an crucial role in establishing customer loyalty, therefore, the following enlightenment on the management can be proposed according to the research conclusions in this thesis:

1) Setting up a bridge of two-way communications and opening up diverse online encounter channels

Research in the thesis shows that both two dimensions of online encounter affect positively the customer experience, though the effect is smaller compared with offline dimensions. However, with the development of mobile internet, encounter of online dimensions will play an increasingly important role in establishing customer loyalty. Theme hotels should at first open up the online and offline communicating channels and set up bridge of communications between hotel and customer through establishment and improvement of platforms such as official website, WeChat and MicroBlog etc., thus improving the quality of online service encounter and laying the foundation for establishing customer loyalty. At the same time, with hotel's own channels being dominant and other channels being subordinate, diverse online encounter channels can be opened up and users with different consumption habits can be satisfied and user engagement can be increased. In addition, hotel should increase the interactivity between platform and customer by opening the interactive function among platforms of WeChat, MicroBlog and official website and establish online customer communication and feedback channels by posting some interactive themes every day to increase the sense of participation of customers to encourage customers to participate, to transmit and to share, making full use of fans benefit to create word-of-mouth marketing and thus establishing good customer loyalty.

2) Improving hardware facility and creating cultural atmosphere with thematic features

Hardware is fundamental. Theme hotel should start from environmental facility,improve hardware facility, pay attention to foster enterprise culture and create culture atmosphere with thematic features, thus increasing experience value of customers and further establishing customer loyalty.In hardware, theme hotels can be improved in terms of five senses of customer. Visually, hotel's architectural style and decoration should match the thematic style and facility should match the theme of hotel. Not only the level of the facility should be paid attention to, but also the quality. Exquisite appearance will provide good experience for customers. Every picture and carving all demonstrate the taste of hotel while we pay attention to the details; for touch, tableware, tables and chairs and bed should make customer feel comfortable. They should not only meet the basic needs of customer, but also can demonstrate a kind of lifestyle; 
acoustically, quietness is essential. Customer coming to hotel hopes to be undisturbed and experience a comfortable style, so the hotel should create relaxing and comfortable experience for customers; for smell, refreshing light fragrance demonstrate quality and taste;for taste, quality of dishes is an important factor in terms of hardware experience of customer. Green and healthy dishes with thematic features will make customers feel our sincerity. In creating cultural atmosphere, theme hotel should excavate distinctive culture of the theme itself and pay attention to fostering of enterprise culture. Culture-rooted building and let enterprise culture permeates all links of service. Pay attention to demonstrate the story behind the theme to customer as place with stories is attractive; at the same time hotel should integrate the thematic culture into experiencing activities to let the customer fully understand the thematic culture in participatory interactive activities to achieve that it's not only selling products but also selling culture, story and idea and Let customer experience the improved hardware facility of the hotel as well as the culture, idea and story of the hotel to meet the deeper needs of customers.

3) Inheriting Craftsmanship and fostering service personnel featuring Changkehua

Craftsmanship pays attention to details and emphasizes excellence and creates remarkable quality with professional and spirit. Hotel should inherit craftsmanship in managing and serving and make service personnel have professional ability by building systematic training system and plan on fostering professional and punctilious service personnel to achieve that they not only can provide standardized service to customer in accordance to specification and procedure professionally, patiently, scrupulously, meticulously and work to the high levels of excellence so that customer can feel that personnel's persistence and pursuance of high quality and be satisfied, but also can identify and excavate the potential needs of customer accurately and quickly to achieve that we can know what customer think of and surprise the customer and increase experience value of customer.

4) Satisfying social needs and creating harmonious relation with customers

People's behaviors will change with the environment. When the overall environment and atmosphere are harmonious, individual in it will also demonstrate good quality, therefore, theme hotel should pay attention to construct harmonious interpersonal relationship in the hotel to meet the demands emotionally and socially. Theme hotel should create warm and sweet and harmonious feelings for customers imperceptibly by harmonious environmental atmosphere in the hotel, neat appearance of service personnel, polite language and positive attitude, which at the same time this will infect the customers and play a demonstration role and then affect the behaviors of customers to achieve that every customer can pay attention to their own appearance, attitude and behaviors, thus establishing good customer relations; at the same time, we can make room specially for customers to share and communicate opened up in hotel room, dining room or main foyer etc. so that customers can share their experience with other customers through many forms such as leaving a message or taking a photo etc.; by using customer interactive function on online platforms such as
WeChat and Microblog, customer can be encouraged to share real-time accommodation experience, which satisfy customer's social needs and elevating customer's emotional functional value.

5) Creating brand of theme hotel and extending industrial chain of theme products

In the time of experience economy, what customer consumed in theme hotel is not only product itself but also the cultural connotation included in the consumption. We focus more on the correlation among brand, personal identity and status. Brand has become one of the core strengths in hotel competition. Brand of theme hotel is not only demonstrated in management, hardware facility, service but also in extension of theme products. Customers coming to theme hotel pursue individuation and at the same time obtain characteristic experience from theme products. Therefore, theme hotel should start from themes, design unique extended theme products, inject elements of cultural creativity, extend industrial chain of cultural products and form our own brand characteristics. Integrate theme culture into hotel's table and chairs, ornaments, daily necessities and commercial goods, turn cultural elements into products, unify highly art and aesthetics to achieve function extension and value elevation of products. Horizontally, products of all departments of hotel should integrate with each other and should be extended in terms of hotel room, catering and service to develop theme products of our own. For example, we can customize selfdeveloped high quality bed for customers, construct an experiential consumer platform featuring online supply and offline experience; longitudinally, unify upstream and downstream enterprises to expand industrial chain system of hotel, such as cooperating with furniture manufacturers. Hotel can select furniture for free use according to its own positioning and liking and at the same time, hotel also can exhibit and sell the furniture for furniture manufacturers by putting price list on places where customers can be close enough to touch. So hotel customers can have a thorough understanding of it, experience, share and customize. In this way, hotel not only decreases cost but also gets advertising, wins customer loyalty and forms its own unique brand advantage.

\section{REFERENCES}

[1] Norman, R. Service management[M].Sweden: John Wiley and Sons, 1984:89

[2] Czepiel, John A., Solomon, Michael. An overview in the service encounter[J].Rervice Encounters, 1985:3-15.

[3] Gutek, Barbara A. The dynamics of Service: Reflections on the Changing Nature of Customer/Provider Interactions[M].san Francisco: Joddey-Bass Publisher,1995.

[4] Lovelock, Christopher H. Services Marketing.[M]. Englewood Cliffs: NJ: 1996,8-12.

[5] Meuter M L, Bitner M J. Self-service technologies: understanding customer satisfaction with technology-based service encounters[J].Journal of Marketing, 2000, 64(3):50-64

[6] Bart Larivière, David Bowen,Tor W. Andreassen, Werner Kunz,Nancy J. Sirianni,Chris Voss,Nancy V. Wünderlich,Arne De Keyser. "Service Encounter 2.0": An investigation into the roles of technology, employees and customers[J]. Journal of Business Research,2017,79.

[7] Zeithaml V A. Consumer perceptions of price, quality, and value: a means-end model and synthesis of evidence[J]. Journal of Marketing, 1988, 52(3):2-22. 
[8] Heskett J L Jones $\mathrm{T}$ O. Putting the service-profit chain to work[J].Harvard Business Review, 1994, 72(2):164-170.

[9] Griffin C. The Internet's expanding role in building customer loyalty[J].Direct Marketing, 1995,59(7):50-53.

[10] Kolter, P., Bowen, J. \& Makens, J. Marketing For Hospitality and Tourism[J].Upper Saddle River, NJ: Prentice Hall.1999:41-45.

[11] Philip Kotler.Marketing Management (10th Chinese version)[M].China Remin University Press, 2001:43

[12] Zhang Fengchao, You Shuyang. Structural Dimensions of Customer Experience Value:DIY Business Perspective[J]. Journal of South China Normal University (Social Science Edition), 2009(4):108-113.

[13] Schmitt, Bernd H.Experiential Marketing[M].New York:The Free Press, 1999:1-150.

[14] Holbrook M B, Kuwahara T, Universityl K. Probing Explorations, Deep Displays, Virtual Reality, and Profound Insights : The Four Faces of Stereographic Three-Dimensional Images in Marketing and Consumer Research[J].Advances in Consumer Research, 1999.

[15] Mathwick C, Malhotra N, Rigdon E. Experiential value: conceptualization, measurement and application in the catalog and Internet shopping environment[J].Journal of Retailing, 2001, 77(1):3956.

[16] Wu, C. H. J \& R. D. Liang. Effect of experiential value on customer satisfaction with service encounters in luxury-hotel restaurants[J].International Journal of Hospitality Management, 2009, 28(4): 586-593.

[17] [17]Li Lei, Jian Zhaoquan.Service Encounter and Service Quality:From Physical Service to Electronic Service[J].Soft Science, $2013,12: 36-40$.
[18] Zhangfang.Study on Impact of Catering Service Encounter under the Circumstances of Mobile Internet on Customer Behavior Intention[D].Zhejiang University,2015.

[19] Li Jianzhou, Fan Xiucheng.An Empirical Research on Three Dimension Service Experiences[J].Tourism Science, 2006, 20(2):5459.

[20] Liu Jinyan.Service encounter based on Customer experience [D]. Naikai University, 2007.

[21] Rust R T, Lemon K N. E-Service and the Consumer[J]. International Journal of Electronic Commerce, 2001, 5(3):85-101.

[22] [22]Jiang Ting.Study on the impact of interaction among customers under the perspective of experience on patronage intentions[D].Jinan: Shandong University, 2012.

[23] Sweeney J C, Soutar G N. Consumer perceived value[J].International Journal of Pharmaceutical \& Healthcare Marketing, 2001, 6(2):167190

[24] Zhao Xiaoxiao. The Study of Consumer's interactive experience value impact on consumer patronage intentions Under the O2Omode-- The food group as an example[D]. Huazhong Agricultural University, 2015.

[25] Zeithaml V A, Berry L L,\& Parasuraman A. The Behavioral Consequences of Service Quality[J].Journal of Marketing, 1996, 60(2):31-46

[26] Yang Jie.Study on the impact of Theme Hotel Customer Experience on Customer Loyalty[D].Shanghai Normal University,2016.

[27] Wu Minglong.Structural Equation Modelling-- Operation and Application of AMOS[M]. Chongqing:Chongqing University Press, 2010. 